\title{
A Dual Model of Ownership
}

\author{
Zeynep Gürgüç ${ }^{*}$ and Robert M. Learney ${ }^{2}$ \\ ${ }^{1}$ Imperial College Business School, London, United Kingdom, ${ }^{2}$ Digital Catapult, London, United Kingdom
}

The transparency and visibility engendered in Distributed Ledger Technology allows, for the first time, disparate stakeholders to agree on common resource existence, ownership, and rules of exchange, while keeping the coordination costs comparatively low with respect to earlier methods. This infrastructure can finally facilitate a selforganizing market mechanism, where people can decide upon the market rules themselves and potentially self-select into any particular marketplace dependent upon their personal beliefs and preferences. Reinventing the apparatus of the economy upon shared distributed infrastructure may finally allow the emergence of actual shared ownership, unlike the existing systems where short-term rentals or access-based consumption are often confused with sharing and social exchange.

Keywords: blockchain, distributed ledgers, ownership, sharing, market design

\section{INTRODUCTION}

\section{OPEN ACCESS}

Edited by:

Martin Zeilinger,

Abertay University, United Kingdom

Reviewed by:

Marc Rocas-Royo,

Open University of Catalonia, Spain Sharvari Chandrashekhar

Tamane,

Jawaharlal Nehru Engineering

College, India

*Correspondence:

Zeynep Gürgüç

z.gurguc@imperial.ac.uk

Specialty section:

This article was submitted to Blockchain for Good, a section of the journal Frontiers in Blockchain

Received: 27 January 2020 Accepted: 17 June 2020

Published: 14 July 2020

Citation:

Gürgüç Z and Learney RM (2020)

A Dual Model of Ownership.

Front. Blockchain 3:30.

doi: 10.3389/fbloc.2020.00030
Fair distribution of resources is notoriously complex, and in a world facing overpopulation, resource depletion, and environmental extremes, the application of free market capitalism to drive these systems may have reached its zenith. Yet private ownership remains "the least bad system we have," to paraphrase Winston Churchill. In order to transition from the competitive capitalistic model which tends toward monopolistic or oligopolistic practices if left unchecked, toward mutually benevolent co-opetition, we must reimagine the fundamental infrastructure of the economy itself.

Issues of ownership, sharing, and access are key concepts within the blockchain debate but they have become particularly relevant in the context of the phenomenon of the "sharing economy." Sharing economy is characterized as an answer to many socio-economic issues by allowing a more sustainable form of consumption, encouraging cooperation, promoting a more equitable distribution of resources, and creating opportunities for micro-entrepreneurs (Martin, 2016). In reality, many of the current structures commonly perceived as "sharing" are in fact market exchange practices with no real shared ownership, which is often referred to as access-based consumption in the relevant literature (Bardhi and Eckhardt, 2012). For example, AirBnB and WeWork's shortterm rentals are often confused with sharing and social exchange, and Uber and ZipCar are in fact selling temporary access to private transportation without any layer of ownership or "sharing."

Interest is growing in new methods of collaborative consumption and shared ownership, which "could be as important as the Industrial Revolution in terms of how we think about ownership" (Belk, 2014b) ${ }^{1}$; however, we still only have limited collective understanding of these concepts. Even though sharing is a separate concept from market exchange practice via access-consumption, companies often "sharewash" their business models to frame actual market exchanges as "sharing" in order to render them more attractive to users and investors (Price and Belk, 2016) $)^{2}$. Too often, the current implementation of the "sharing economy" is one

\footnotetext{
${ }^{1}$ See Botsman and Rogers (2010) for their discussion.

${ }^{2}$ Please refer to the introduction and the articles for the special issue on "Consumer Ownership and Sharing" at the Journal of the Association for Consumer Research for an extensive debate these topics.
} 
of time-partitioning access to private property owned by another individual or organization, and extracting rent from managing the marketplace where these events occur.

There are, however, some good models of shared ownership wherein all participants coordinate to derive benefits greater than those possible from the contributions of the individual. The clearest examples include time-sharing for holiday rentals or certain financial products. Only by attracting the financial contributions of multiple parties into a unifying structure (the management organization) are the parties able to secure land, develop property, and then return the benefit of proportionate residency to the original contributors. However, there are many counterexamples of the same structures being abused for excessive rent-seeking which ultimately leads to a collapse of the beneficial organization. Coordinating stakeholders and correctly assessing the necessary management costs against the benefits provided (partially fungible access rights to desirable holiday locations) requires individuals to have more complete knowledge and capabilities to assess risk than is currently possible. A similar model is seen in mutual funds, but here competition and regulatory compliance often ensure that management fees are kept to a necessary minimum, and that the management only profits alongside the investors.

The transparency and visibility engendered in Distributed Ledger Technology allows, for the first time, disparate stakeholders to agree on common resource existence, ownership, and rules of exchange, while keeping the coordination costs comparatively low with respect to earlier technologies. The infrastructure offered by Distributed Ledger Technology allows for a self-organizing market mechanism, where people can now decide upon the market rules themselves and potentially self-select into any particular marketplace dependent upon their personal preferences. Reinventing the apparatus of the economy upon shared distributed infrastructure may even allow the emergence of economic systems independent of the prevailing political system in a particular state.

\section{A HISTORY OF PRIVATE OWNERSHIP AND ITS LIMITATIONS}

Concepts of ownership and private property are the fundamental building blocks of capitalism. Current ownership structures arise from the concepts of rivalry and excludability, which are also critical in distinguishing private from public goods. Pure private goods are excludable and rival; whereas on the opposite end, we have public goods that are non-excludable and non-rival.

Throughout history, human societies have repeatedly and independently self-organized beneath the purview of governing individuals (kings or religious leaders) or groups (governments) with authority to declare rules for managing the limited resources in the natural world around them. Humans are certainly altruistic, even toward non-human animals, but we are bad at efficiently allocating common resources. We therefore use rules and regulations to resist the depletion of common resources, that is, the tragedy of the commons.
The very earliest societies capable of writing began to codify rules around trade, and punishments for misdeeds against property, including theft or fraud. The Code of Hammurabi from 1754BCE - the earliest surviving legal document-contains particular reference to these topics, clearly indicating respect for private property rights. In economic terms, these laws enforced the excludability of private ownership. Protection of private property rights allowed people to partition resources in an efficient, but not necessarily equitable way.

Many economists agree that private ownership is often preferable to public ownership in order to boost innovation by enabling an innate selfish profit-motive ${ }^{3}$ to drive particular individuals (Marshall, 1907; Samuelson, 1948; Shleifer, 1998, among many others). Similarly, private-for-public mechanisms are often more efficient than simple state provision of public goods. Shleifer (1998) argues that "The case for private provision only becomes stronger when competition between suppliers, reputational mechanisms, the possibility of provision by private not-for-profit firms, as well as political patronage and corruption, are brought into play." However, the selfish profit-motive can also push certain individuals/entities toward excessive productivity. Accordingly, unchecked private ownership through ineffectual regulation can lead to the formation of oligopolies or monopolies, to the detriment of innovation and the wider economy.

There are some industries, however, where the market structure naturally evolves toward a monopoly or an oligopoly (Joskow, 2007). Natural monopolies arise when it is actually more efficient for a single firm to coordinate production due to high fixed costs, leading to high barriers to entry for competitors. These market structures are typically seen when we are dealing with goods that are excludable but not necessarily rival. Some positive examples are seen with various infrastructure industries, including energy supplies (gas and electricity provision), transportation (rail) and telecommunications. These industries are often either publicly owned or heavily regulated by the state in order to bound their economic rent.

The arguments around natural monopolies and how they should be regulated are less straightforward in the context of the digital economy. Tech giants have innovated significantly and created numerous tools to facilitate our lives. Substantial externalities and economies of scale have given rise to dominant players or natural monopolies as they grew larger thanks to direct and indirect network effects ${ }^{4}$ (Tirole, 2017). Tirole ${ }^{5}$ argues that "Monopolies are not ideal, but they deliver value to the consumers as long as potential competition keeps them on their toes. They will be then forced to innovate and possibly even to charge low prices... But for such competition to operate, two conditions are necessary: Efficient rivals must, first, be able to

\footnotetext{
${ }^{3}$ Note that profit in this case is not exclusively financial-it can also be professional, intellectual, relationship, or status-driven amongst other intrinsic motivating factors. Few humans are motivated by pure beneficence.

${ }^{4}$ Direct effects happen when we directly benefit from having other users on the platform, e.g., access to many Uber drivers. Indirect effects happen when the platform services improve due to the existence of other users on the platform, e.g., traffic predictions.

${ }^{5}$ For a good interview with Jean Tirole on natural monopolies in the digital economy, please refer to https://qz.com/1310266/nobel-winning-economist-jeantirole-on-how-to-regulate-tech-monopolies/.
} 
enter and, second, enter when able to." However, in reality, we often see that many potential competitors are bought out at very early stages by an incumbent rather than growing to compete against it. Tirole ${ }^{6}$ goes on to state: "such entries for buyout create very little social value as they are mainly a mechanism for the entrant to appropriate a piece of the dominant firm's rent."

Additionally, natural monopolies of this digital era are also the owners of multitudes of personal data, which causes significant concerns regarding individual privacy and security. Negative externalities stemming from these concerns lead us to question the limitations of private ownership and the concentration of power in the hands of a few tech giants, or the "curse of bigness" as put forth by Louis Brandeis.?

\section{LIMITED RESOURCES, PSEUDO-SHARING, AND PLATFORMS}

In theory, Web 2.0 allowed for new platform-based business models that enable collaborative consumption and sharing. Frequently, access-based consumption facilitated via shortterm rentals or online barter economies are positively perceived as "sharing" by the public (Cherry and Pidgeon, 2018). However, we often see that platforms, which provide mediated peer-to-peer "sharing," actually provide pseudosharing practices where no actual sharing or transfer of ownership takes place (Lovelock and Gummesson, 2004; Bardhi and Eckhardt, 2012; Belk, 2014a; Cherry and Pidgeon, 2018). Such platforms are essentially designed for rent-seeking, and promote a system of platform capitalism ${ }^{8}$ (Srnicek, 2017) rather than sharing or social exchange (Sandoval, 2019), which leads to contrasting narratives. On the one hand, one may argue that they enable a lower cost of entry and hence fairer labor markets; on the other hand, they decrease the bargaining power of workers and deepen existing inequalities (Pasquale, 2016).

Unequivocally, however, these systems offer access to almost everything except ownership. According to Scholz (2017), the current sharing economy is "really an on-demand service economy that set out to monetize services that were previously private" or inaccessible. Instead, he proposes platform cooperativism, a model of democratically owned and governed cooperatives operating on the Internet (Scholz, 2014, 2017).

Access-based consumption facilitated by web 2.0 platforms may seem a plausible and efficient way to utilize depleting resources in an environment where it is becoming prohibitively difficult to fully own certain goods. However, not only does this system exacerbate the aforementioned inequalities, it also fails to provide individuals a long-term safety net. Alternative ownership structures including cooperatives, corporations, mutual funds,

\footnotetext{
${ }^{6}$ Ibid.

${ }^{7}$ Brandeis argued that monopolies should be eliminated since the existence of large centers of private power was dangerous to the continuing vitality of free people living in a democratic society.

${ }^{8} \mathrm{~A}$ term coined by Sascha Lobo (https://www.spiegel.de/netzwelt/netzpolitik/ sascha-lobo-sharing-economy-wie-bei-uber-ist-plattform-kapitalismus-a989584.html)
}

and partnerships are types of actual shared ownership that are used to grant participants a sense of income security. Moreover, when it comes to management of common resources, there are many different viable mechanisms between fully private and fully public where users of the common resource self-organize or govern effectively (Ostrom, 1990).

As mentioned previously, time-shares for holiday rentals constitute a good example of actual shared ownership, but in their current state, they do not provide much flexibility to the owner, especially not in terms of changing the time periods where the property is assigned to a certain individual. This is because time allocations are not truly fungible. Peak summer and national or religious holidays will often be highly desirable, and individual parties will not allocate exactly the same priority to every period available. This system can be improved upon with the introduction of side-payments to allow temporary exchanges of time-slots among current owners of time-shares for funding or other considerations, to reflect individual priorities. DLTs and smart contracts can help us keep track of these arrangements, particularly payments, in a transparent manner while executing them automatically.

\section{SHARED OWNERSHIP ENABLED BY DLT}

Distributed ledgers are time-sequenced, non-repudiable, and unforgeable records of state. These can be combined with programmable logic to regulate state transitions, and cryptographic proofs of existence. These features can for the first time minimize externalities (including knowledge imbalance) and coordination costs for enforcing digital scarcity and thus rivalry and excludability in the digital space.

This enables a shift from privately owned timeshare models to true communally owned assets and valuation. A number of features at the heart of these systems are critical to enabling this future:

1. The Byzantine-fault tolerant consensus process underpinning (certain) DLTs ensures the ledger maintains a single view of current state and historic stateful information even against purposeful efforts to cause inconsistencies.

2. Distribution between multiple stakeholders, alongside the responsibilities for maintaining and finalizing stateful information, enlarges the attack surface to prevent any single actor from modifying data without significant collusion.

3. Appropriate selection of cryptographic methods can be used to prove the existence and awareness of critical information at a given moment in time.

We will explore these properties in two use-case scenarios on electric vehicles and energy trading. Consider a potential future model of DLT being used to enable (i) electric vehicle shared ownership and (ii) vehicle recharging and peer-to-peer energy trading. 


\section{Scenario 1: Shared Vehicle Ownership}

Imagine three friends called Ana, Bea, and Charlie who live in the same neighborhood. They all occasionally need a car but do not each require sufficiently frequent usage to warrant individual ownership; however, they need it frequently enough that renting becomes excessively costly, and deprivation of access at heavy usage periods can be detrimental. They are all interested in accessing an electric vehicle but they realize that they do not have the necessary funds to purchase one each. They discuss among themselves to register for one of the access-based car consumption schemes; however, because they live in a relatively remote area there are not enough service providers that offer access-based consumption; hence, they elect to cooperatively own the car using a future public DLT-based system, or perhaps one held between various non-colluding car companies.

This takes place in three phases:

1. Funding checks and risk modeling are performed on Ana, Bea, and Charlie using encrypted personal data sets to ensure their ability to collaboratively own the vehicle.

2. A digital "twin" of the vehicle is created on the ledger to represent the physical entity (still a challenge).

3. Ownership of the vehicle is partitioned into proportionate shares and passed to Ana, Bea, and Charlie.

Ana, Bea, and Charlie can each hold a key that gives them access to the car via a smart lock. They can now pick up the car from a specific location and keep it in their neighborhood at a specified charging point. Based on their shares for the car, they can all book their slots for the car in a shared calendar, their shared-based usage can be monitored via a smart contract and once they reach their monthly quota, their key is disabled. They can negotiate with each other via other smart contracts and a side payment, for example, to reprioritize extra usage this month in exchange for less usage next month.

Additionally, the servicing of the car can be allocated to each owner via a calendar system again managed through a smart contract, and when one of the owners does not fulfill his/her responsibility for the period his/her associated smart lock can be disabled. The faulty owner can then be penalized by losing usage time the following month. The ledger can additionally maintain an immutable record of the car's condition, which is also useful if any or all of the owners of the car decides to sell the car or their share. Insurers can be given access to these records to assess the insurance cost for the car.

The traditional model of managing non-excludability in this scenario would rapidly result in intermediaries seeking payment for coordinating all the actors and trust relationships. This is because current models of vehicle ownership do not enable multiple unlinked individuals to fund and allocate access to the resource without acting through a third party (a private company). This is due to the inefficiencies in managing risk profiling, financial background checks, vehicle maintenance, access logs and controls, and all other aspects of vehicle ownership. It is more efficient for the vehicle manufacturer and financing body to pass these responsibilities to a private company in the current environment.
These coordination costs are vastly reduced by the unique properties of DLT - a non-repudiable auditable chain of liability held between relevant non-colluding parties, trustless smart contracts to manage state transitions, and cryptographically assured permissions.

\section{Scenario 2: Vehicle Recharging and Peer-to-Peer Energy Trading}

Given that one of the main challenges for EV adoption is the lack of widespread charging solutions, this infrastructure can also be enhanced via the use of DLTs. In this scenario, DLTs can enable a multi-owner virtualized national common market for offering, finding, and accepting access to recharging far more efficiently than centrally administered services with large manpower overheads, office space, and profit motives. Owners of charging points can use the market to make their energy supply available to other users, and users can pay atomically for each unit of energy consumed, logged via DLT. Once the vehicle is plugged in and funds are verified, a smart contract can initiate the recharge cycle for a vehicle that is plugged in, and ensure that stateful data regarding who, where, when, and how long, are suitably recorded in an encrypted format. Individuals could even pay on their own personal electricity bill even if recharging in a friend's driveway.

There are critical elements in this scenario of future collaborative ownership which are only efficient through the use of DLT and cryptography.

The provision of electricity supply to private dwellings or public recharging points is handled through private companies as vehicles of structural convenience to ensure liability rests with a named party in the event that there is a requirement to seek legal redress for grievances. This is not too dissimilar to the previous scenario. These structures are enforced in current regulations, which are hindering the further evolution of the electricity market from a centralized natural monopoly to a decentralized marketplace in common ownership.

If instead the provision and consumption of electricity across shared physical infrastructure was coordinated through a DLT, society could minimize the externalities requiring private companies to act as legal intermediaries. The ledger, combined with appropriate cryptographically signed proofs, would provide an indelible record of the history of momentary apportionment of legal entitlement and liabilities regarding energy provision and consumption, and track all transfers of said liabilities. Such an unforgeable and transparent shared record acts as an incorruptible, dispassionate, and universal observer of economic activity and property rights, enabling disintermediated communal ownership and allocation of electricity resources.

Based on a case study using blockchain to mitigate shortcomings in the electricity charging market due to trust issues, Gorenflo et al. (2019) states that "In the end, we could even have a system where there is machine-tomachine communication rather than people-to-machine. If an autonomous vehicle needs power, it could detect that and drive to the nearest charging station and communicate on a platform with that charging station for the power." 


\section{THE LIMITS OF SHARED OWNERSHIP}

With DLT acting as a highly accessible and low-friction method for coordinating economic actors, the past three years has seen a Cambrian Explosion of systems and marketplaces to enable novel forms of asset ownership. While there are technical and regulatory limits to the models that can be built and/or adopted at present, we must ask whether there are limits to the types of ownership models that should be built. We must not fall victim to a fallacy that all ownership models built with this technology will be benevolent.

We present a counterexample to the benefits of fractionalizing ownership of a non-fungible asset (electric vehicles), in the form of fractionalized home ownership.

A number of start-ups have emerged within the DLT ecosystem proposing fractional home ownership as a means of enabling (i) low earners to part-own and accrue ownership of a high value asset currently beyond their reach and (ii) a novel financial portfolio for the wealthy. We believe, however, that enabling such forms of fractional ownership for a primary residence come with far greater negative externalities than have been appreciated to date.

First, while it may be possible to digitally fractionalize home ownership to create a novel asset class that appears fungible, the rights of occupancy cannot be fractionalized. There is no such condition as proportional or accrued occupancy of a primary or sole residential dwelling. The end result of fractional occupancy is in fact more akin to a time-share or hotel. Contrary to the belief that this will improve home ownership, this will instead remove housing stock from the existing market and concentrate the value of real estate in the hands of current owners.

Second, we cannot ignore the historic reality of ratcheting in the housing market. 100 years ago, housing was affordable to average families with only a single working adult. Following the financialization of the 1980s, average home ownership required two working adults. As of 2020, countries such as Australia, Hong Kong, Norway, and the United Kingdom are now experimenting with partial ownership for families of two working adults ("shared" with the state), with multiple negative reports in the media. Facilitating mechanisms to allow fractional ownership by selfish non-state co-owners will further separate the attainability of home ownership from those on average incomes, and may lead to sizable negative economic impacts.

\section{CONCLUDING REMARKS}

Over millennia of steady natural population growth tempered by a lack of resources, humans have continually learned to overcome the limits of the world around them. In the past 500 years, this growth has seemingly broken free, driven by the ready access to labor (domestic and enslaved), resources (native or captive), and energy (freeing productivity from "manpower"). This growth has been accompanied by a number of simultaneous shifts in demographics, borders, population centers, and industrialization. However, many are now questioning the maximal extent of such extractive behaviors. The growth of environmentalism and other previously "fringe" positions such as veganism are indications that humans are in search of a system where resources are more efficiently and sustainably utilized, often coupled with a desire for more equitable distribution.

Distributed ledgers hold promise for reducing the coordination costs associated with building novel public and private ownership models, enforcing rivalry through digital uniqueness, and excludability through smart contracts to manage access. Distributed ledgers potentially provide a new type of infrastructure for market design where market participants can self-select into the system with their preferred model of ownership; and even self-govern. DLTs can facilitate communal ownership structures in localized areas or within specific sectors worldwide. This may lead to a future in which individuals have the freedom to digitally live in their preferred economic and ownership system no matter where they physically reside, independent of the ideology of the regional government.

To demonstrate the effect of DLT infrastructure in ownership structures and market design, we have presented two viable use-case scenarios-electric vehicle ownership, and a novel marketplace for energy trading. We have not considered issues of oraclization, nor have we fully parameterized the limits of ownership enabled by DLT. These are still active areas of debate and development. Oraclization speaks to the source of truth for events occurring outside the distributed ledger. Examples include the recording of weather reports from a trusted agency, which could be digital in nature, or the cleanliness of the electric vehicle after a previous occupant has used it.

We have invited the reader to consider the limits of ownership enabled by DLT. While it may be technically possible to fractionalize the ownership of an asset, the rights inherently associated with that asset may not in fact be fractionalizable, particularly if normal usage of that good is rivalrous on normal human time scales. As with the first example, I may be able to exclusively access a vehicle for a period of a weekend, but my co-owners will eventually be able to exclude my access for similar periods of time. This is likely to cause only minor and short-lived inconvenience to myself. I can always take a taxi, or hire a different vehicle. Dwelling rights within a primary or sole residential home, however, are not settled on the same timescales, and are not fungible with alternative accommodation.

\section{AUTHOR CONTRIBUTIONS}

Both authors contributed to the structuring of the idea, analysis, and the writing of the manuscript.

\section{FUNDING}

The authors would like to thank the Researcher in Residence Program at Digital Catapult funded by EPSRC EP/M029263/1. 


\section{REFERENCES}

Bardhi, F., and Eckhardt, G. M. (2012). Access-based consumption: the case of car sharing. J. Consum. Res. 39, 881-898. doi: 10.1086/666376

Belk, R. (2014a). Sharing versus pseudo-sharing in Web 2.0. Anthropologist 18, 7-23. doi: 10.1080/09720073.2014.11891518

Belk, R. (2014b). You are what you can access: sharing and collaborative consumption online. J. Bus. Res. 67, 1595-1600. doi: 10.1016/j.jbusres.2013. 10.001

Botsman, R., and Rogers, R. (2010). What's Mine is Yours: The Rise of Collaborative Consumption. London: Collins.

Cherry, C. E., and Pidgeon, N. F. (2018). Is sharing the solution? Exploring public acceptability of the sharing economy. J. Cleaner Prod. 195, 939-948. doi: $10.1016 /$ j.jclepro.2018.05.278

Gorenflo, C., Golab, L., and Keshav, S. (2019). "Mitigating trust issues in electric vehicle charging using a blockchain," in Proceedings of the Tenth ACM International Conference on Future Energy Systems, New York, NY, 160-164. doi: $10.1145 / 3307772.3328283$

Joskow, P. L. (2007). Regulation of Natural Monopoly. Handbook of Law and Economics, Vol. 2, Burlington, NJ: Elsevier Science, 1227-1348. doi: 10.1016/ S1574-0730(07)02016-6

Lovelock, C., and Gummesson, E. (2004). Whither services marketing? In search of a new paradigm and fresh perspectives. J. Serv. Res. 7, 20-41. doi: 10.1177/ 1094670504266131

Marshall, A. (1907). The social possibilities of economic chivalry. Econ. J. 17, 7-29.

Martin, C. J. (2016). The sharing economy: a pathway to sustainability or a nightmarish form of neoliberal capitalism? Ecol. Econ. 121, 149-159. doi: 10. 1016/j.ecolecon.2015.11.027

Ostrom, E. (1990). Governing the Commons: The Evolution of Institutions for Collective Action. Cambridge: Cambridge university press.
Pasquale, F. (2016). Two narratives of platform capitalism. Yale Law Policy Rev. 35:309.

Price, L. L., and Belk, R. W. (2016). Consumer ownership and sharing: introduction to the issue. J. Assoc. Consum. Res. 1, 193-197. doi: 10.1086/68 6270

Samuelson, P. A. (1948). Economics, an Introductory Analysis. New York, NY: McGraw-Hill.

Sandoval, M. (2019). Entrepreneurial activism? Platform cooperativism between subversion and co-optation. Crit. Sociol. doi: 10.1177/0896920519 870577

Scholz, T. (2014). Platform cooperativism vs. the sharing economy. Big Data Civic Engagem. 47-53.

Scholz, T. (2017). Uberworked and Underpaid: How Workers are Disrupting the Digital Economy. Cambridge: Polity.

Shleifer, A. (1998). State versus private ownership. J. Econ. Perspect. 12, 133-150. doi: $10.1257 /$ jep.12.4.133

Srnicek, N. (2017). Platform Capitalism. Hoboken, NJ: John Wiley \& Sons.

Tirole, J. (2017). Economics for the Common Good. Princeton, NJ: Princeton University Press.

Conflict of Interest: The authors declare that the research was conducted in the absence of any commercial or financial relationships that could be construed as a potential conflict of interest.

Copyright $\odot 2020$ Gürgüç and Learney. This is an open-access article distributed under the terms of the Creative Commons Attribution License (CC BY). The use, distribution or reproduction in other forums is permitted, provided the original author(s) and the copyright owner(s) are credited and that the original publication in this journal is cited, in accordance with accepted academic practice. No use, distribution or reproduction is permitted which does not comply with these terms. 